\title{
Acute Respiratory Infections in Travelers Returning from MERS-CoV-Affected Areas
}

\section{Matthew German, ${ }^{1}$ Romy Olsha, Erik Kristjanson, Alex Marchand-Austin, Adriana Peci, Anne-Luise Winter, Jonathan B. Gubbay}

We examined which respiratory pathogens were identified during screening for Middle East respiratory syndrome coronavirus in 177 symptomatic travelers returning to Ontario, Canada, from regions affected by the virus. Influenza $A$ and $B$ viruses $(23.1 \%)$ and rhinovirus $(19.8 \%)$ were the most common pathogens identified among these travelers.

$\mathrm{M}$ iddle East respiratory syndrome coronavirus (MERS$\mathrm{CoV}$ ) was originally described in 2012 in a patient with severe pneumonia in Saudi Arabia (1). The virus has been detected in several countries of the Middle East, causing acute respiratory disease and having a case-fatality rate of $\approx 35 \%$ (2). Although the exact epidemiology and mode of transmission remains ill-defined, MERS-CoV appears to be transmitted through respiratory droplets and most likely has zoonotic reservoirs in dromedary camels and possible origin in bats (1). Recent evidence suggests human infection results from repeated introduction of the virus from camels to humans, and less severe human-to-human transmission probably requires close contact with infected persons $(2,3)$.

As of June 16, 2015, the World Health Organization (WHO) reported 1,293 laboratory-confirmed cases of MERS-CoV, of which 458 (35.4\%) were fatal, and ongoing transmission in Saudi Arabia (2). Reported cases are centralized in and around the Arabian Peninsula (Saudi Arabia, United Arab Emirates [UAE], Iran, Jordan, Kuwait, Lebanon, Oman, Qatar, and Yemen); Saudi Arabia and UAE account for $\approx 95.8 \%$ of cases (2). Internationally, imported cases have been reported outside this zone (United Kingdom, France, Germany, Tunisia, Italy, Malaysia, Philippines, Greece, Egypt, United States, the Netherlands, Algeria, Austria, and Turkey) (2). Within Saudi Arabia and UAE, cases are predominantly localized to Jeddah, Riyadh, and Abu Dhabi, each of which operates a high-traffic airport that serves 17-26 million international travelers each year $(4,5)$. To detect imported MERS-CoV cases, public health authorities in Ontario, Canada, advises testing of persons who have acute respiratory infection (ARI; i.e., symptoms and signs consistent with acute upper or lower respiratory tract infections) of any severity and recent travel to MERS$\mathrm{CoV}$-affected areas or of persons with ARI and recent close contact with ill travelers from affected areas (6).

Author affiliation: Public Health Ontario, Toronto, Ontario, Canada

DOI: http://dx.doi.org/10.3201/eid2109.150472
Peak travel periods to Saudi Arabia (e.g., Ramadan, Umrah, or the Hajj) are of particular concern, although after the 2012 and 2013 Hajj, no MERS-CoV cases were identified in persons returning to France (7). High incidences of other respiratory diseases in pilgrims varied by year. In this study, we aimed to explore the array of respiratory pathogens in travelers with ARI returning to Ontario from MERS$\mathrm{CoV}$-affected areas or in their close symptomatic contacts.

\section{The Study}

During November 2012-June 2014, a total of 177 international travelers returning to Ontario were considered persons under investigation (PUIs) for MERS-CoV, according to the guidelines of the Ontario Ministry of Health and Long-Term Care (6). PUIs were recommended to be isolated and screened for MERS-CoV and other respiratory pathogens (6).

Nasopharyngeal swab samples and, for persons on ventilators, bronchoalveolar lavage specimens were collected from patients and submitted to Public Health Ontario Laboratories (PHOL), the provincial reference laboratory for MERS-CoV testing (6). Fecal specimens were collected when patients had diarrhea, and urine was collected during early phases of the outbreak when appropriate specimens were ill-defined (6).

MERS-CoV real-time reverse transcription PCR (rRTPCR) targeted regions upstream of the $\mathrm{E}$ gene and within open reading frame $1 \mathrm{~b}$, as recommended by $\mathrm{WHO}(8)$. Influenza rRT-PCRs targeted the influenza A matrix gene and influenza B nonstructural 1 gene using Centers for Disease Control and Prevention (CDC; Atlanta, GA, USA) protocols. If the rRT-PCR was positive for influenza A virus, we conducted subtyping for seasonal influenza $\mathrm{A}(\mathrm{H} 3 \mathrm{~N} 2)$ virus hemagglutinin gene (CDC assay) and influenza $\mathrm{A}(\mathrm{H} 1 \mathrm{~N} 1)$ pdm09 virus neuraminidase gene (in-house assay) (9). Respiratory specimens were further tested by using Seeplex RV15 ACE multiplex respiratory viral assay (Seegene Inc., Seoul, South Korea). Targets included human rhinovirus, enterovirus, influenza A and B viruses, parainfluenza viruses $1-4$, respiratory syncytial virus $A$ and $B$, adenovirus, bocavirus, human metapneumovirus, human coronavirus OC43, and human coronavirus 229E/NL63. Mycoplasma pneumoniae and Chlamydophila pneumophila testing was conducted by using ProPneumo-1 multiplex assay (GenProbe Inc., San Diego, CA, USA). PCR was conducted for Legionella species by using a protocol developed by CDC (10); BinaxNOW Legionella Urinary Antigen Test (Binax

${ }^{1}$ Current affiliation: St. Michael's Hospital, Toronto, Ontario, Canada. 


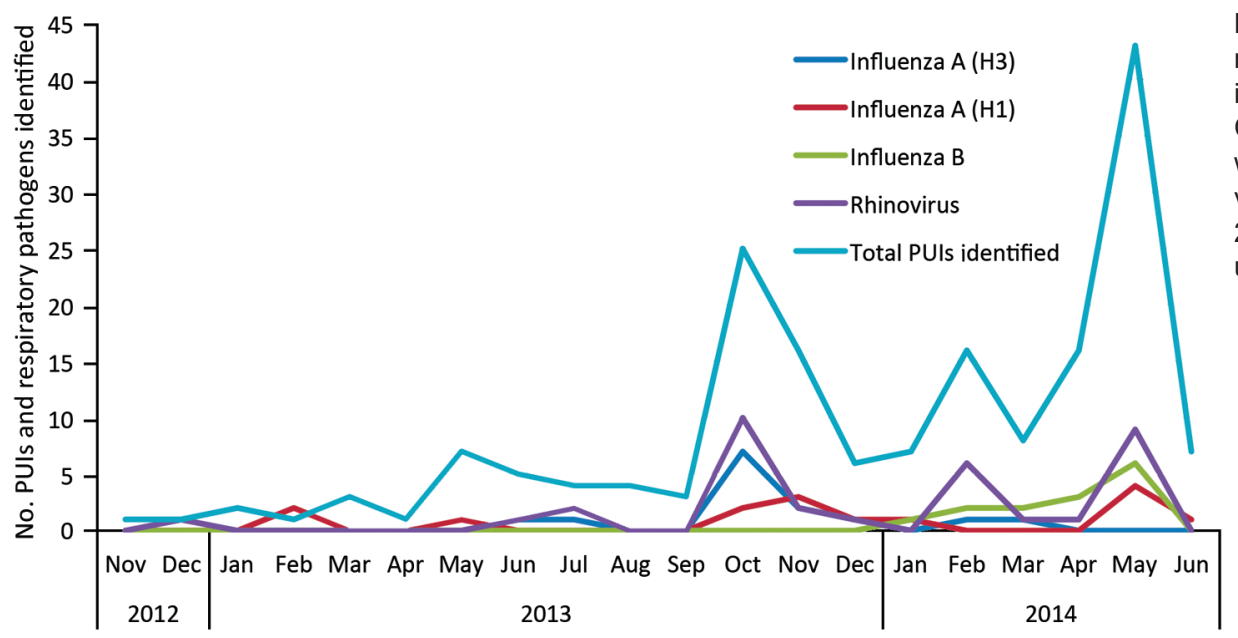

Figure. PUls and counts of major respiratory pathogens identified in travelers returning to Ontario, Canada, from countries affected with Middle East respiratory virus coronavirus, December 2012-June 2014. PUI, persons under investigation.

Inc., Portland, ME, USA) was also conducted to test for $L$. pneumophila serogroup 1.

Of 177 PUIs (mean age 48.1 years, range $<1-88$ years; $56 \%$ male), 54.8\% returned from Saudi Arabia or UAE. Identification of PUIs peaked after the October 2013 Hajj and after the first 2 MERS-CoV cases were imported into the United States in May 2014 (Figure). All PUIs had ARI; of the 85 PUIs for whom data were available, 47 (55\%) and $74(87 \%)$ had respiratory specimens collected within 5 and 14 days (median 4 days) from symptom onset, respectively. Specimens collected were as follows: 185 upper respiratory, 10 lower respiratory, 98 urine, 97 blood, 11 fecal, and 1 pleural fluid. Symptom onset varied from 17 days before return to 10 days after return (median $\leq 1$ day after return) for the 20 PUIs for whom this information was supplied. One patient was excluded from the time-to-collection analysis because the specimen was collected under extenuating circumstances: testing was conducted because of worsening respiratory symptoms beginning 57 days before the patient returned from overseas.

At least 1 respiratory pathogen (bacterial or viral) was detected in 89 (50.3\%) PUIs; however, for most (87 [98\%] of 89) patients, only viral pathogens were identified (Table). Influenza was the most common virus identified: $27(15.3 \%)$ persons tested positive for influenza A, 14 (7.9\%) for $\mathrm{A}(\mathrm{H} 3 \mathrm{~N} 2)$ and $13(7.3 \%)$ for $\mathrm{A}(\mathrm{H} 1 \mathrm{~N} 1) \mathrm{pdm} 09$;

Table. Respiratory pathogens detected among 177 persons tested for MERS Co-V at Public Health Ontario Laboratories, Ontario, Canada, November 2012-June 2014*

\begin{tabular}{|c|c|c|c|}
\hline \multirow[b]{2}{*}{ Pathogen† } & \multicolumn{3}{|c|}{ Case count } \\
\hline & No. $(\%) \ddagger$ & Highest no. imported in $1 \mathrm{mo}$ & Time of highest no. \\
\hline \multicolumn{4}{|l|}{ Influenza viruses } \\
\hline Influenza A $(\mathrm{H} 3)$ virus & $14(7.9)$ & 7 & 2013 Oct \\
\hline Influenza $\mathrm{A}(\mathrm{H} 1 \mathrm{~N} 1)$ pdm09 virus & $13(7.3)$ & 4 & 2014 May \\
\hline Influenza B virus & $14(7.9)$ & 6 & 2014 May \\
\hline \multicolumn{4}{|l|}{ Other respiratory viruses } \\
\hline Rhinovirus & $35(19.8)$ & 10 & 2013 Oct \\
\hline Parainfluenza viruses $1-4$ & $5(2.8)$ & 1 & NA \\
\hline Human metapneumovirus & $4(2.6)$ & 2 & 2014 May \\
\hline Respiratory syncytial virus (A and B) & $4(2.6)$ & 1 & NA \\
\hline Enterovirus & $1(0.6)$ & NA & NA \\
\hline Adenovirus & $1(0.6)$ & NA & NA \\
\hline Bocavirus & 0 & NA & NA \\
\hline \multicolumn{4}{|l|}{ Human CoVs } \\
\hline Human CoV OC43 & $6(3.4)$ & 3 & 2014 Feb \\
\hline Human CoV 229E/NL63 & $2(1.1)$ & 1 & NA \\
\hline MERS-CoV & 0 & NA & NA \\
\hline \multicolumn{4}{|l|}{ Bacteria } \\
\hline Chlamydophila pneumoniae & $1(0.6)$ & NA & NA \\
\hline Legionella spp. & $1(0.6)$ & NA & NA \\
\hline Mycoplasma pneumoniae & 0 & NA & NA \\
\hline
\end{tabular}

${ }^{*} \mathrm{CoV}$, coronavirus; MERS, Middle East respiratory virus; NA, not applicable.

†Among the 177 returned travelers, no respiratory pathogen was found for $88(49.7 \%)$. Among the remaining $89(50.3 \%)$ returned travelers, at least 1 respiratory pathogen was found; $12(6.8 \%)$ of these persons had viral co-infections. Among the 12 co-infections were 8 rhinovirus co-infections (4 persons with influenza A and 1 each with influenza B, enterovirus, CoV OC43, parainfluenza); 1 influenza A-CoV OC43 co-infection; 1 influenza B-respiratory syncytial virus; 1 CoV 229E/NL63-adenovirus; and 1 CoV 229E/NL63-human metapneumovirus co-infection.

†Comprises all reported infections, including viruses that were involved in co-infections. 
$14(7.9 \%)$ tested positive for influenza B. Rhinovirus was also common, detected in $35(19.8 \%)$ persons, with a peak in the fall, in keeping with its seasonality in Canada (Figure; Table). Similarly, influenza A(H3N2) peaked in the fall, whereas influenza $\mathrm{B}$ and $\mathrm{A}(\mathrm{H} 1 \mathrm{~N} 1) \mathrm{pdm} 09$ peaked in late spring.

No specimen submitted to the PHOL tested positive for MERS-CoV. Given the relatively low volume of travelers arriving to Canada and Ontario from MERS-CoV-affected areas $(0.6 \%$ of total global travel from MERS-CoV-affected areas entered Canada during June-November, 2012, and $<50,000$ nonresident travelers entered Ontario from affected countries in 2012 [11,12]) and lower rates of humanto-human transmission, risk of importation to Ontario and subsequent local spread is likely low $(1,13)$.

\section{Conclusions}

Although the risk for MERS-CoV importation is low, respiratory virus infections acquired abroad or locally after returning to Canada might be relatively high and consistent, occurring in 87 (49.2\%) of 177 PUIs during the study period. Most influenza B cases were detected shortly after the 2014 Ontario peak (PHOL, unpub. data). Furthermore, $75 \%$ of PUIs with influenza B reported symptom onset within 4 days after their return, possibly indicating local acquisition. Similarly, PUIs with enterovirus or rhinovirus detected probably acquired disease in Canada, given the short incubation period (mean 1.9 days) of rhinovirus (14).

Because limited information about clinical severity or outcomes was reported to PHOL, we were unable to report on the clinical spectrum of PUI presentation. Furthermore, pathogens were not identified for all samples, possibly because of delays between symptom onset and specimen collection, sampling technique, or other factors.

The number of PUIs with influenza (41 [23.2\%]), whether acquired locally or abroad, is of particular concern. Unnecessary identification of PUIs might have been avoided with more comprehensive vaccination coverage. Influenza vaccination should be a priority for all persons and should be recommended by health care practitioners who advise travelers. In addition, surveillance should continue for other respiratory pathogens so that their effects on health systems, when they co-circulate with emerging pathogens with similar clinical presentation, can be better understood.

\section{Acknowledgments}

We are thankful to Public Health Ontario and PHOL technical staff for support and help with data collection.

This work was funded by Public Health Ontario.

Mr. German is an infectious disease epidemiologist at St. Michael's Hospital in Toronto, Ontario. His research interests include global migration and emerging and re-emerging infectious disease.

\section{References}

1. Sharif-Yakan A, Kanj SS. Emergence of MERS-CoV in the Middle East: origins, transmission, treatment, and perspectives. PLoS Pathog. 2014;10:e1004457. http://dx.doi.org/10.1371/journal.ppat.1004457

2. World Health Organization. Global Alert and Response (GAR). Middle East respiratory syndrome coronavirus [cited 2015 Mar 10]. http://www.who.int/csr/disease/coronavirus_infections/en/

3. World Health Organization. Update on MERS-CoV transmission from animals to humans, and interim recommendations for at-risk groups [cited 2014 Dec 23]. http://www.who.int/csr/disease/ coronavirus_infections/MERS_CoV_RA_20140613.pdf?ua=1

4. The Kingdom of Saudi Arabia General Authority of Civil Aviation. Statistical yearbook, 2013 [cited 2014 Jul 15]. http://www.gaca.gov.sa/GACA/Attachments/020/A835/1/ The_report_of_2013_En.pdf

5. Abu Dhabi Airports. Traffic data-2013 [cited 2014 Jul 16]. http://www.adac.ae/english/doing-business-with-us/ airline-development/traffic-data/traffic-data-2013

6. Provincial Infectious Diseases Advisory Committee. Tools for preparedness: triage, screening and patient management for Middle East respiratory syndrome coronavirus (MERS-CoV) infections in acute care settings; 4th ed [cited 2015 May 1]. http://www.publichealthontario.ca/en/eRepository/PIDAC-IPC_ Preparedness_Tools_MERS_CoV_2013.pdf

7. Benkouiten S, Charrel R, Belhouchat K, Drali T, Nougairede A, Salez N, et al. Respiratory viruses and bacteria among pilgrims during the 2013 Hajj. Emerg Infect Dis. 2014;20:1821-7. http://dx.doi.org/10.3201/eid2011.140600

8. Corman VM, Eckerle I, Bleicker T, Zaki A, Landt O, Eschbach-Bludau M, et al. Detection of a novel human coronavirus by real-time reverse-transcription polymerase chain reaction. Euro Surveill. 2012;17:20285.

9. Duncan C, Guthrie JL, Tijet N, Elgngihy N, Turenne C, Seah C, et al. Analytical and clinical validation of novel real-time reverse transcriptase-polymerase chain reaction assays for the clinical detection of swine-origin H1N1 influenza viruses. Diagn Microbiol Infect Dis. 2011;69:167. http://dx.doi.org/10.1016/ j.diagmicrobio.2010.09.020

10. Yang G, Benson R, Pelish T, Brown E, Winchell JM, Fields B. Dual detection of Legionella pneumophila and Legionella species by real-time PCR targeting the 23S-5S rRNA gene spacer region. Clin Microbiol Infect. 2010;16:255. http://dx.doi.org/10.1111/ j.1469-0691.2009.02766.x

11. Khan K, Sears J, Hu VW, Brownstein JS, Hay S, Kossowsky D, et al. Potential for the international spread of Middle East respiratory syndrome in association with mass gatherings in Saudi Arabia. PLoS Curr. 2013;5:pii: ecurrents.outbreaks. a7b70897ac2fa4f79b59f90d24c860b8.

12. Statistics Canada. Table 427-0006. Number of non resident travellers entering Canada, by selected country of residence, excluding the United States, seasonally adjusted monthly (persons) [cited 2015 Mar 12]. http://www5.statcan.gc.ca/cansim/ a26?lang $=$ eng \&id $=4270006 \& p 2=17$

13. Drosten C, Meyer B, Marcel MA, Corman VM, Al-Masri M, Hossain R, et al. Transmission of MERS-coronavirus in household contacts. N Engl J Med. 2014;371:828-35. http://dx.doi.org/ 10.1056/NEJMoa1405858

14. Lessler J, Reich NG, Brookmeyer R, Perl TM, Nelson KE, Cummings DA. Incubation periods of acute respiratory viral infections: a systematic review. Lancet Infect Dis. 2009;9:291-300. http://dx.doi.org/10.1016/S1473-3099(09)70069-6

Address for correspondence: Matthew German, St Michael's HospitalLi Ka Shing Knowledge Institute, 209 Victoria St, Toronto, ON M5B

1T8, Canada; email: germanm@smh.ca 